\title{
Concept of Palliative Care in Intensive Care Units
}

\author{
Jelena Hodak* \\ Department of Anaesthesiology, Resuscitation and Intensive Care, University Hospital Centre Zagreb, Croatia
}

Submission: October 26, 2018; Published: November 13, 2018

*Corresponding author: Jelena Hodak, Department of Anaesthesiology, Resuscitation and Intensive Care, University Hospital Centre Zagreb, Kišpatićeva 12, 10000 Zagreb, Croatia

\begin{abstract}
Some patients who are admitted to the intensive care unit face the terminal phases of the disease, which ultimately leads to death. Advanced knowledge of palliative care is recommended for all healthcare professionals dealing with these patients. In many situations, patients need to evaluate their needs on a daily basis, as the introduction of further interventions may not be useful to them. Co-operation of health team members regarding the overall care goals needs to be carefully assessed in collaboration with patients and their families. Adoption of endof-life protocols in intensive care units is the most important step in improving the quality of care. A multidisciplinary team is a key factor in determining the necessary advanced care. In addition, patients and families should be told that palliative care includes the best possible care for this specific situation as well as respect for their desires and social and spiritual needs. Therefore, the aim of this paper is to present palliative care as a support to health professionals in intensive care units in providing terminal patients care. A new concept of work according to the hospice model as an alternative to intensive care and the hospital environment should also be directed.
\end{abstract}

Keywords: Palliative care;Intensive care unit;Concept

\section{Introduction}

The World Health Organization has announced that only 14\% of those who are in need around the world receive palliative care [1]. Due to the high technology available in intensive care units for advanced life support, palliative care and intensive care has become a challenge. Therefore, immediate intensive care should be balanced between the palliative and the critical conditions that can be treated [2]. In addition, the primary purpose of intensive care unit should not only be to promote aggressive treatment; it should also help patients and families make wise decisions about life [3]. Therefore intensive care physicians and nurses need adequate training to fulfill this fundamental and current approach [4]. At present, the presence of palliative care is an accreditation element adopted by health care quality agencies and used to select the best clinical centers [5]. Palliative care in intensive care units supports patients and families and can provide a better environment, better care and increased life-long awareness [6].

\section{Discussion}

Communication between intensive care unit staff and patients and family members is often inadequate. Recent studies have shown a dissatisfied family with communication [7]. The quality of this communication is directly related to family satisfaction with treatment [8]. Patients and family communication can be severe in intensive care units because of severity of the disease, medical complications, high risk of death and limited medical knowledge of the family. Efforts to improve the quality and quantity of this information (when the patient is stable) improves the effectiveness of intensive care, reduces the burden of patient care over their lifetime and reduces the burden on families and healthcare workers [9]. There is little available research on family interactions with staff in intensive care units. A systematic approach to day-to-day communication can be effective in these situations. Good communication is an essential part of medical practice in intensive care units. The key elements are the identification of consistent medical and family individuals; setting a regular time for daily information; defining the main problems initially and how the clinical course proceeds; recognition and respect for patient care; and summarize and consistently communicate. After initial patient assessment and stabilization, the first family information, it is important to familiarize family members, identify key decision-makers, report initial assessments and diagnostic plans, assess the existence of advanced directives, and plan subsequent agreements. Many individuals did not have experience with critically ill family members. It is useful to explain organizational patterns and care about intensive care and to explain the roles and hierarchy of care teams. Planned information is useful only after visiting, handing over the service and after performing one part of the care.

A consistent communicator for each patient can provide reduced ambiguity and confusion. This allows for direct 
observation of the patient's interaction and an opportunity to hear the discussion about the possibilities of assessment and care. If there are no such guidelines, the family may be advised to consider what their relative could choose if they were fully aware of the circumstances. Efficient communication can facilitate continuous care [10]. Clinical advances in intensive care units can be focused later on discussions on status, care needs, or palliative care options. Families know that their beloved person has received the best care options and that their wishes are respected. This approach is effective if the outcome is complete recovery, death in JIL or transition to palliative care. The definition of dying with dignity recognizes unconditional internal human values, such as body comfort, quality of life, autonomy, meaning, preparation and interpersonal relationships. Preserving dignity, avoiding unwanted events, preventing and resolving conflicts are the responsibilities of intensive care personnel in charge of the patient [2]. There is a paradigm shift, with emphasis on relieving the suffering of a sick person instead of a person's illness.

The usual therapeutic approach should be defined on the basis of previous discussions among the multidisciplinary team of ICU, including all that deal with the patient. This will avoid uncertainty for patients and families. This proactive approach to communicating with palliative patients and families reduced residence and hospitalization times in ICU. Care emphasizes the quality of the last days of life in relation to its amount [11]. Communication with the family should be based on the confidence and clear understanding that withdrawal or retention of life support is not related to withdrawal or retention of care [12].

\section{Conclusion}

Mortality in intensive care units is still high, and the health care team in intensive care units is constantly faced with complex situations in which advanced life-long life will not reach the goal of avoiding death nor respects the patient's and family's desires. The key is the cooperation of all health professionals with multidisciplinary team involved in patient care. We must be prepared to discuss the limitations of technology for the treatment and palliative care of patients and their families. Hospitals should develop protocols for complex cases, which also include a number of experts and respect for ethical aspects.

\section{References}

1. Davies E, Higginson IJ (2004) Better Palliative Care for Older People. World Health Organization Regional Office for Europe, p. 43.

2. Cook D, Rocker G (2014) Dying with dignity in the intensive care unit. N Engl J Med 370(26): 2506-2514.

3. Searight HR, Gafford J (2005) Cultural diversity at the end of life: issues and guidelines for family physicians. Am Fam Physician 71(3): 515522 .

4. Soares M (2011) End of life care in Brazil: the long and winding road. Crit Care 15(1): 110-110.

5. The Joint Commission (2016) Benefits of certification for palliative care. USA.

6. Clary PL, Lawson P (2009) Pharmacologic pearls for end-of-life care. Am Fam Physician 79(12): 1059-1065.

7. You JJ, Dodek P, Lamontagne F, Downar J, Sinuff T, et al. (2014) What really matters in end-of-life discussions? Perspectives of patients in hospital with serious illness and their families. CMAJ 186(18): E679687.

8. Anderson WG, Chase R, Pantilat SZ, Tulsky JA, Auerbach AD (2011) Code status discussions between attending hospitalist physicians and medical patients at hospital admission. J Gen Intern Med 26(4): 359366.

9. Curtis JR, Vincent JL (2010) Ethics and end-of-life care for adults in the intensive care unit. Lancet 376(9749): 1347-1353.

10. Soares M (2007) Caring for the families of terminally ill patients in the intensive care unit. Rev Bras Ter Intensiva 19(4): 481-484.

11. Campbell ML, Guzman JA (2003) Impact of a proactive approach to improve end-of-life care in a medical ICU. Chest 123(1): 266-271.

12. DeLisser HM (2010) How I conduct the family meeting to discuss the limitation of life-sustaining interventions: a recipe for success. Blood 116(10): 1648-1654.

\section{Your next submission with Juniper Publishers will reach you the below assets}

- Quality Editorial service

- Swift Peer Review

- Reprints availability

- E-prints Service

- Manuscript Podcast for convenient understanding

- Global attainment for your research

- Manuscript accessibility in different formats

( Pdf, E-pub, Full Text, Audio)

- Unceasing customer service

Track the below URL for one-step submission https://juniperpublishers.com/online-submission.php 